\title{
MUSICAL HALLUCINATIONS IN A PATIENT WITH MULTIPLE CARDIOVASCULAR RISK FACTORS
}

\author{
M. Roque Pereira, A. Fornelos, A.R. Figueiredo \\ CHTMAD-EPE- Hospital de São Pedro, \\ Departamento de Psiquiatria e Saúde Mental, \\ Vila Real, Portugal.
}
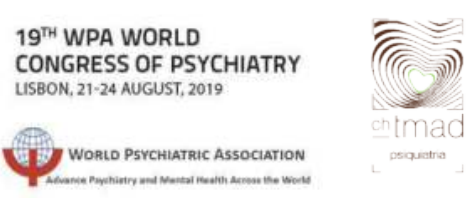

Sometimes normal musical imagery crosses a line and becomes disturbing or pathologic.

Earworms, aka "stuck song syndrome“, may appear suddenly, full-blown, taking instant and entire possession of one, they may also develop by a sort of contraction, from previously normal musical imagery. Earworms resemble intrusive thoughts that are usually stereotyped and invariant in character. They tend to have a certain life expectancy, going full blast for hours or days and then dying away, apart from occasional afterspurt. ${ }^{(1,2,3,4)}$

Those who consider music to be important to them report earworms as longer, and harder to control, than those who consider music as less important. The tunes which produce these experiences vary considerably between individuals but are always familiar to those who experience them. (4)

Auditory hallucinations are most often verbal hallucinations. Phenomenological surveys have also shown that a substantial minority of people also report musical hallucinations. (1) Auditory hallucinations can be simple (unspecific sound, in the form of tinnitus) or complex (more elaborate, of a more complex content, most often verbal).

Musical Hallucination constitutes a complex type of auditory hallucination in which the perception of said hallucination can be in the form of tunes, melodies, music or songs. They have a prevalence of approximately $0.16 \%$, but they are likely underreported. They occur more often in elderly women with impaired hearing. ${ }^{(1,2)}$

They are frequently associated with hypoacusia, severe psychiatric illnesses (such as depression, schizophrenia, and OCD), cerebral lesions (stroke, tumours, multiple sclerosis, and other), temporal lobe epilepsy and other neurological disorders. They can also be a side-effect of some medications (such as hypotensive drugs, tricyclic antidepressants, Antimalarials and other), and Lyme and Hashimoto diseases. (1)

The treatment depends on the underlying cause.

\section{CLINICAL VIGNETTE}

A 74 year old woman was evaluated in the emergency room with depressed mood and insomnia as chief complaints. Anamnesis revealed uncontrollable church music inside her head for over three months. The musical hallucinations were mood incongruent.

The woman had had a profoundly catholic cultural background. She had diabetes, hypertension, and atrial fibrillation. She also had mild hypoacusia. Imagiological findings revealed a left temporal lobe focal lesion secondary to ischemia. There were no other findings in diagnostic tests including EEG.

She was treated with an SSRI and low dose sedative antipsychotic medication. When reviewed in consultation, she was euthymic and no longer appalled by what she kept listening in a milder way. She came to accept what she called "god's music".

Till date, her musical hallucinations could not be better explained, suggesting that her hallucinations were not psychotic but neurological, or potentially of multiple causes. Table 1.

\begin{tabular}{|c|c|}
\hline \multicolumn{2}{|c|}{ ETIOLOGY OF MUSICAL HALLUCINATIONS } \\
\hline Auditory Deprivation & \multirow{6}{*}{$\begin{array}{l}\text { Our patient had mild auditory } \\
\text { deprivation, } \\
\text { Our patient was depressed, but } \\
\text { her hallucinations did not } \\
\text { disappear with euthymia. } \\
\text { Our patient had a focal brain } \\
\text { lesion } \\
\text { Our patients EEG was normal. } \\
\text { Our patient was chronically on } \\
\text { antidiabetics and hypotensive } \\
\text { drugs, classes that have been } \\
\text { associated to MH, but none were } \\
\text { recently introduced. } \\
\text { No toxic-metabolic causes were } \\
\text { found. }\end{array}$} \\
\hline Psychiatric Disorders & \\
\hline $\begin{array}{r}\text { Focal brain lesions and } \\
\text { cerebral atrophy }\end{array}$ & \\
\hline $\begin{array}{r}\text { Epilepsy } \\
\end{array}$ & \\
\hline Drugs & \\
\hline Toxic-metabolic causes & \\
\hline
\end{tabular}

Table 1. Possible causes of Musical hallucinations and discussion of our clinical vignette

\section{"It really is a very odd business that all of us, to varying degrees, have music in our heads." - Oliver Sacks}

References: 1. Perez PA, Garcia-Antelo MJ, Rubio-Nazabal E. "Doctor, I Hear Music": A Brief Review About Musical Hallucinations. Open Neurol J. 2017; 11: 11-14. 2. Moseleya P, Alderson-Daya B, Kumarc S. Musical hallucinations, musical imagery, and earworms: A newphenomenological survey. Conciousness and Cognition. Volume 65, 